\title{
A IMIGRAÇÃo COMO RISCO PARA A SAÚdE: UMA ANÁlISE DAS REPRESENTAÇÕES DO IMIGRANTE AFRICANO NA CObertura da Folha de S. PAUlo SObRe O Ébola
}

\author{
Igor Sacramento \& Izamara Bastos Machado
}

\begin{abstract}
Resumo
Neste artigo analisamos a construção de estereótipos sobre os imigrantes africanos na Folha de S. Paulo durante a cobertura do surto epidémico de ébola no continente africano, em 2014. Damos especial atenção ao modo como o jornal noticiou o caso de suspeita de contágio do imigrante guineense Soulyname Bah. Observamos que houve, por meio da lógica do medo, um processo de marcação identitária expressa na oposição entre "nós" e "eles", promovendo a repulsa à diferença pela ressignificação das características da etnia africana enquanto marcador de risco à saúde. Na sociedade do risco, a cobertura jornalística sobre o ébola - e de outras pandemias - revela um paradoxo crucial da nossa época: o apogeu de avanços científicos humanos que, apesar de tudo, não têm necessariamente atenuado os nossos medos e pânicos sobre potenciais perigos. Nesse contexto, a imigração configura-se como uma questão de segurança e é entendida como uma pluralidade de ameaças (terrorismo, crime, doença e desemprego). Dessa forma, como concluímos neste trabalho, a securitização da imigração é um processo que substitui a consideração de problemas sociais estruturais por práticas discursivas, tecnológicas e institucionais que permitem a identificação e a responsabilização de grupos específicos.
\end{abstract}

\section{Palavras-chave}

Migração; risco; estereótipo; ébola; jornalismo

\section{INTRODUÇÃO}

O ano de 2014 registou o maior surto de contaminação por ébola desde a descoberta do vírus, em 1976. Segundo dados da Organização Mundial de Saúde (OMS) tinham sido registadas, até ao mês de dezembro de 2014, 6.583 mortes de um total de 18.188 casos identificados na África Ocidental. Esse surto da doença, iniciado em dezembro do ano anterior na Guiné, avançou nos meses seguintes para a Libéria, Serra Leoa, Nigéria e Senegal. A partir daí, intensificou-se a preocupação com a possibilidade de uma pandemia de ébola, notória nos vários meios de comunicação e nas organizações internacionais de saúde, à escala mundial (OMS, 2014).

À medida que a doença alastrava, ficava patente no debate público o "problema" da relação entre o ébola e as migrações. Jean-Marie Le Pen, fundador do partido de extrema-direita francês Frente Nacional (FN), chegou a afirmar que o surto de ébola poderia resolver, tanto o problema da "explosão populacional" do mundo, como o da imigração para a Europa (Folha de S. Paulo, 2014, 22 de maio, p. 2). Com efeito, alguns setores mais conservadores de países ocidentais têm vindo a apresentar a migração como estando associada ao aumento dos riscos interferindo, assim, sobre a economia, 
a política, o emprego, a residência, a segurança e a saúde dos residentes. A imigração surge frequentemente definida como "um problema fundamental, e nunca como um desafio, muito menos como um benefício para o país, frequentemente é associada a um fardo financeiro" (Van Dijk, 2010, p. 146). No entanto, é comum a imprensa escamotear o debate racial em tópicos relacionados com a violência urbana, o terrorismo, problemas sanitários, o desemprego, o uso e ao tráfico de drogas (Silva \& Rosemberg, 2014). A notícia da Folha de S. Paulo sobre o posicionamento de Le Pen em nenhum momento identifica, aliás, a questão racial que fica subsumida ao binómio segurança/risco.

O nosso objetivo neste artigo é analisar o modo como o jornal brasileiro Folha de S. Paulo, ao cobrir o surto de ébola, constituiu a imigração africana como "fator de risco" para a saúde. Para entendermos essa articulação, dividimos o texto em três partes: na primeira abordamos sinteticamente as associações contemporâneas entre estereótipo, imigração e risco na sociedade global; na segunda, apresentamos uma sistematização da cobertura da Folha de S. Paulo sobre o surto de ébola em 2014, considerando as mudanças nas narrativas na medida em que a doença foi encarada como uma possível ameaça ao Brasil; na última, analisamos o papel do discurso jornalístico na construção do imigrante guineense Soulyname Bah como o Outro, demonstrando as articulações entre a representação estereotipada e a definição de fatores de risco à saúde.

Embora a teoria do risco esteja tradicionalmente centrada em questões de tecnologia e meio ambiente (Beck, 2010; Giddens, 2001), outros estudos têm aplicado a teoria do risco na análise da representação dos média sobre as questões da imigração e do corpo imigrante (Bradimore \& Bauder, 2011). Com base na semiologia dos discursos sociais, mostraremos como se deram as diferentes estratégias discursivas e os efeitos de sentido produzidos na separação entre "nós" (saudáveis/ameaçados) e "eles" (doentes/ameaçadores) e suas conexões com um processo de estereotipização do Outro. $O$ papel da análise de discursos, neste contexto, não é identificar se há risco em termos estatísticos, mas sim, salientar como determinados objetos enunciativos se tornam especialmente interpretados como "arriscados" e como essa classificação de risco se torna significativa e partilhada dentro de uma sociedade. Em síntese, importa perguntar: Que ações simbólicas tomam lugar para construir o Outro como factor de risco? Que condições permitiram que determinados sujeitos se tornassem entendidos como "fatores de risco", devendo ser temidos, controlados, gerenciados e até mesmo excluídos do convívio social?

Escolhemos a Folha de S. Paulo por ser um dos jornais impressos de referência nacional e de maior circulação no território brasileiro (dados da Associação Nacional de Jornais/ANJ). De acordo com a Associação Nacional de Jornais, em 2013 (último ano disponível no site da Associação) o jornal ocupou a segunda posição no ranking, com uma média de circulação de 294.811.' O segundo motivo da escolha prende-se com o facto de ser considerado um dos jornais de grande relevância política e de ampla capacidade de

\footnotetext{
' De acordo com a ANJ entre os anos de 2002 e 2009 a Folha de S. Paulo ocupou, consecutivamente, a primeira posição no ranking. Posição que se repetiu em 2012. Nos anos de 2010, 2011 e 2013, o jornal paulista perdeu a primeira posição para o jornal mineiro Super Notícia. Acedido em http://www.anj.org.br/maiores-jornais-do-brasil.
} 
formação de opinião no Brasil. E, por fim, por se tratar de um dos jornais monitorados pelo Observatório Saúde nos Média, do qual fazemos parte como pesquisadores. ${ }^{2}$

\section{ESTEREÓTIPO E IMIGRAÇÃo NO CONTEXTO DA GLOBALIZAÇÃO DO RISCO}

Para se refletir sobre o processo de construção da imigração como fator de risco à saúde no âmbito da cobertura realizada pela Folha de S. Paulo sobre o surto de ébola na África, é importante problematizar a própria noção de risco na contemporaneidade (Sacramento \& Lerner, 2015).

Beck (2010) assinala que o risco é uma característica fundamental da modernidade tardia. Segundo o autor, na "sociedade do risco", nem a ciência, nem a política no poder, nem os media, nem empresas, nem a lei nem mesmo os militares estão em condições de definir ou controlar os riscos de forma racional. Como bem observou o autor, a generalização da incerteza coexiste com "disputas definitórias" em torno da extensão, do grau e da urgência dos riscos, numa luta simbólica entre media, ciência, empresas, governos. Afinal, o mundo moderno aumenta a diferença entre a linguagem dos riscos calculáveis sobre os quais pensamos e agimos e o mundo do não-calculável da incerteza e do imponderável que nós criamos com a mesma velocidade dos seus desenvolvimentos tecnológicos. Com as últimas decisões sobre a energia nuclear, o uso da tecnologia genética, a nanotecnologia, a ciência da computação e assim por diante, partimos para um conjunto de consequências imprevisíveis, incontroláveis e incomunicáveis que podem até mesmo colocar em perigo a vida na terra. Vivemos, dessa forma, um contexto marcado por paradoxos e contradições que delineiam o recrudescimento simultâneo de responsabilidade e irresponsabilidade, conhecimento e ignorância, autonomia e dependência, segurança e risco (Matheus, 2010, pp. 136-137).

No mundo contemporâneo, a segurança está associada à confiança: é preciso confiar nos dispositivos, nas instituições e nas pessoas para considerá-los como "lugares seguros", áreas de segurança, num mundo dominado por incertezas, inseguranças, riscos e desconfianças. Para Giddens (2001, p. 16), a modernidade tardia é concomitante com o surgimento de oportunidades muito maiores para os seres humanos gozarem de uma "existência segura e gratificante" do que qualquer sistema pré-moderno. Mas ela também tem um "lado sombrio", carregado de perigos e ameaças à vida, como conflitos, guerras, ataques terroristas, acidentes nucleares, crises ambientais, epidemias e pandemias (Giddens, 2001, p. 17). Nesse sentido, a contemporaneidade carateriza-se por uma ambiguidade na qual observamos, de um lado, um contexto de insegurança, gerado pela permanência da ameaça e, de outro, a existência de narrativas e instituições que

\footnotetext{
${ }^{2}$ Criado em 2008, o principal objetivo do Observatório Saúde na Mídia - projeto localizado no Laboratório de Pesquisa em Comunicação e Saúde (Laces), do Instituto de Comunicação e Informação Científica e Tecnológica em Saúde (ICICT), da Fundação Oswaldo Cruz (Fiocruz) - é realizar análises sobre os modos pelos quais os meios de comunicação de massa produzem sentidos sobre o Sistema Único de Saúde (SUS) - sistema de saúde público brasileiro - e quais os temas específicos da saúde, bem como contribuir para a luta pela democratização da comunicação na sociedade em geral e, na saúde, em particular. O Observatório prevê a monitorização diária de alguns periódicos impressos de grande circulação no país: no Rio de Janeiro: O Globo, O Dia; em São Paulo: Folha de S. Paulo e O Estado de S. Paulo; em Brasília: Correio Braziliense; em Recife: Jornal do Comercio e Folha de Pernambuco.
} 
prometem formas de proteger a população, como, por exemplo, o discurso científico em suas diferentes disciplinas. Em relação às instituições, observamos o recrudescimento de práticas e serviços de segurança a diferentes níveis, desde a vigilância de espaços até procedimentos biomédicos (câmaras de vigilância, identificações biométricas, monitorização e recolha de dados na internet, política de privacidade na rede, mapeamento do genoma, descoberta de doenças e produção de vacinas). Na dimensão narrativa, há a proliferação do uso da retórica do risco no relato de acontecimentos e experiências envolvendo epidemias, crimes, catástrofes e acidentes. Particularmente no jornalismo, a narrativa do medo indica uma característica ética e política central nas culturas ocidentais contemporâneas: a tendência é apenas "aceitar o sacrifício no presente quando são construídas as consequências negativas associadas ao não-sacrifício" (Vaz et al., 2012, p. 27). Ou seja, as narrativas jornalísticas tendem a estimular fortemente a audiência "a se conceber na mesma condição daquele que sofre, o que desloca a busca da responsabilidade pelo sofrimento para um personagem Outro" (Vaz et al., 2012, p. 29). É assim que se pode produzir um nexo de responsabilidade entre quem sofre e quem faz sofrer.

A questão-chave em muitas áreas da vida quotidiana não é apenas a experiência concreta de incontrolabilidade, mas, sobretudo, a perda de credibilidade e confiança, desintegrando o ideal orientador da racionalidade e controle modernos (Beck, 2010). Afinal, o risco adquiriu nas sociedades ocidentais contemporâneas um estatuto ontológico, tornando-se uma entidade autónoma, objetivável, independente dos complexos contextos socioculturais" (Castiel et al., 2010, p. 25). A definição do que é perigoso, assim como os tipos das medidas de proteção e de prevenção fogem ao controle da racionalidade científica, mesmo que ainda sejam referenciados como dados objetivos, precisos e livres de interferências. Como observou Beck (2010), existem interesses e pontos de vistas concorrentes dos grupos, agentes e instituições envolvidos na definição dos riscos. Nesse sentido, a pretensão de racionalidade das ciências para determinar objetivamente os fatores de risco refuta-se a si mesma permanentemente. É cada vez mais recorrente, por exemplo, que determinado alimento ou medicamento seja considerado tanto como benéfico, como maléfico à saúde. Nessa atual dinâmica social os estudos e evidências científicas dependem ainda mais intensamente das expetativas e avaliações sociais na definição dos riscos. Essa pluralidade conflitual de definições, com origens institucionais distintas (média, empresas, setores industriais, entidades científicas, órgãos governamentais, organizações não-governamentais), demonstra o quanto a validade social precisa estar associada a uma série de habilidades argumentativas (Gonçalves, 2004).

Tal mutação, na forma de experiência prática das definiç̧ões científicas sobre os riscos, produz representações e narrativas sobre doenças, no quadro de públicos globais, sob a lógica do risco: ameaçadoras e essenciais para estabelecer a moralidade no mundo contemporâneo (Lerner \& Sacramento, 2012; Sacramento \& Lerner, 2015; Sacramento \& Ribeiro, 2014; Vaz et al., 2007). Nesse sentido, a experiência mediatizada de catástrofes, pandemias e guerras atuais e potenciais tornou-se uma dimensão fundamental, em que tanto a interdependência e as ameaças à existência humana como o seu futuro precário incidem sobre a vida quotidiana. Sendo assim, em termos normativos, há a frequente 
constituição do Outro, do "eles", do estranho que ameaça e impede continuidade da ordem.

No contexto da sociedade de risco, os fluxos e mobilidades humanas ao redor do globo são com mais frequência interpretados na ótica do paradigma da suspeição. Afinal, embora a globalização seja em grande parte teorizada em termos de fluxos transnacionais de pessoas, tecnologias, finanças, informações, culturas e ideologias (por exemplo, Appadurai, 1996; Castels \& Miller, 1998; Castells, 1999; Massey, 1993), é preciso considerar que também existem processos sistémicos de segregação e de contenção (Shamir, 2005). Há, portanto, pressões sociais, estruturas disciplinares e dispositivos legais que procuram delimitar a mobilidade global (Turner, 2007). Destacam-se práticas cada vez mais quotidianas de "suspeição generalizada" que fundem, por exemplo, as ameaças percebidas de crime, desemprego, doenças, imigração e terrorismo e os fluxos migratórios, constituindo, assim, um modelo normativo de organização de estratégias globais de gestão de risco (Shamir, 2005). O regime de mobilidade que carateriza as sociedades globais convive com a suspeição generalizada, desencadeando práticas de controlo, como o aumento da vigilância nas fronteiras, a proliferação de condomínios fechados, a monitorização de dados e de indivíduos, a espionagem e a construção de perfis biossociais. Ao falar sobre um paradigma de suspeita, Shamir (2005, p. 201) observa que o princípio primário para determinar a "licença para se mover", quer a nível inter-fronteiriço, quer em espaços públicos no interior das fronteiras, tem a ver com o grau pelo qual os agentes da mobilidade são socialmente considerados suspeitos de representar ameaças de imigração indesejada, de crimes, de terrorismo e de proliferação de doenças.

É por isso que a securitização é uma das principais caraterísticas das sociedades contemporâneas (Muller, 2004; Shamir, 2005; Turner, 2007). Como já comentamos, este processo implica a proliferação de protocolos e dispositivos de segurança nas mais diversas instituições e espaços da vida social, envolvendo práticas como a revista em presídios, o uso de crachás e a necessidade de identificação para circular em prédios comercias e públicos, a inspeção em aeroportos, a exacerbação do controle das fronteiras, o aumento nas exigências para vistos de permanência ou naturalização de imigrantes, a maior rigidez nas entrevistas para migração, e assim por diante.

Nesse processo de suspeição generalizada, a securitização das sociedades modernas produz formas significativas de imobilidade. Ao nível das práticas quotidianas, há muitos exemplos. Por vezes, são até tidos como benignos: vagões exclusivos para muIheres, ou quartos privados em hospitais públicos. As causas da ascensão da "sociedade enclausurada" são numerosas: a globalização do crime e da doença, "o retorno do Estado", a securitização, a migração ilegal, a paranoia política, inovações técnicas e assim por diante (Turner, 2007). Basicamente, a perceção crescente nas democracias liberais contemporâneas é a de que a cidadania, ou a questão de quem é capaz e quem não o é de ser um membro de uma determinada comunidade política, tornou-se, de facto, numa questão de segurança. Esta consciência tem andado de mãos dadas com a "securitização do interior" que significa a perceção de imigrantes, refugiados e estrangeiros como ameaças sociais à ordem política e social da cidadania nacional (Muller, 2004). 
Há, nesse contexto, a emergência de um novo tipo de xenofobia. Como esclarece Turner (2007, pp. 299-300), com o desenvolvimento dos movimentos diaspóricos, o estranho está tanto próximo quanto distante, porque está envolvido numa rede global de comunidades que se estendem por todo o mundo. No território nacional, as diferenças culturais tornam-se institucionalizadas e produzem grupos sociais excluídos, em guetos e periferias, com subempregos e poucas oportunidades.

A constituição de estereótipos tem vindo a ser uma das principais estratégias discursivas na fixação dos imigrantes como ameaças, associando diferenças étnicas a mecanismos de repúdio, exclusão e desqualificação. Os média são certamente o espaço simbólico privilegiado de construção de representações nas sociedades contemporâneas. Como parte da representação do quotidiano, os produtos da cultura dos média, por meio de suas imagens e demais signos, podem contribuir, entre outras atividades, para construir a confiança em instituições e práticas de segurança e a perceção da diferença do Outro como próxima ou distante, familiar ou exótica, dependendo de contextos socioculturais determinados (Silverstone, 2002). Em relação aos imigrantes e à imigração tem sido muito comum, especialmente nos meios de comunicação europeus, a estreita conjugação entre gangues juvenis, bairros degradados e insucesso escolar e as hierarquias e imaginários coloniais (Cabecinhas, 2007). Há na cobertura jornalística, uma forte presença do imigrante pelo viés do estereótipo (Ferin, 2009).

O objetivo dos estereótipos é interpretar o Outro como uma população de tipos degenerados com base numa retórica essencialista, a fim de justificar a superioridade e estabelecer sistemas de administração, instrução e exclusão (Bhabha, 1998). A essencialização é o grande fundamento para a demonização. Agora, finalmente, pode-se compreender qual a função subjacente à demonização: serve para "atribuir a culpa aos outros, servindo igualmente como base para a projeção nos outros daquilo que nos deixa inseguros e ansiosos" (Young, 1971, p. 210). Os efeitos da demonização acontecem através de um mecanismo de desumanização dos indivíduos e dos grupos (os mais pobres, os imigrantes, os dependentes químicos). Afinal, os estereótipos "naturalizam, através da associação de determinadas características a pessoas e grupos, os atributos, generalizando o que é particular, particularizando o que é próprio de situações gerais" (Ferin, 2009, p. 199). Os média têm a função de "sintetizar e simplificar a informação, facilitando a identificação de referentes e permitindo aos públicos que reconheçam situações e tipos sociais insiders ou outsiders" (Ferin, 2009, p. 199).

Nesse sentido, os estereótipos são como que um efeito do poder - uma estratégia discursiva que tenta estabelecer determinadas posições do sujeito como fixas e que, muitas vezes, degeneram tipos como uma forma de legitimar hierarquias e desigualdades sociais (Hall, 1997, p. 238). Ou seja, é por intermédio dos significados produzidos pelas representações que se dá sentido à experiência, àquilo que se é e àquilo em que nos podemos tornar. Afinal, como ratifica Woodward (2000, pp. 17-18), "os discursos e os sistemas de representação constroem os lugares a partir dos quais os indivíduos podem se posicionar e a partir dos quais podem falar". Trata-se de um processo que, no caso das representações mediáticas dos imigrantes, promove a diferenciação entre 
aquilo que é conhecido (tomado como familiar, adequado, bom, correto, o "nós") e o que é desconhecido (considerado exótico, estranho, mau, errado, o "não nós", "eles"). Nessa construção da alteridade, são "eles" quem sempre ameaçam a "nós".

Os estereótipos empregam uma estratégia de cisão, transformando em excluídos aqueles que não se encaixam nas normas da sociedade e que estão inseridos num conjunto de indivíduos considerados inaceitáveis - o Outro (Hall, 1997). Certamente, a estereotipagem é um processo complexo que nos permite categorizar as pessoas de uma forma significativa, a partir de experiências anteriores que permitem identificar características similares. Isto é geralmente feito com as pessoas e não é, por definição, negativo. Por exemplo, atribuímos certas características para papéis como "pai", "homem de negócios", "pensionista", e assim por diante. Enquanto classifica as pessoas de uma maneira similar, reduzindo-as a características simplificadas e exageradas, a estereotipagem tende a não admitir qualquer possibilidade de mudança, originando a ideia de que tais características são naturais. Afinal, em essência, os estereótipos declaram "isto é o que você é, e isso é tudo que você é" (Hall, 1997, p. 259).

$\mathrm{Na}$ tensão entre a mobilidade e a segurança que caracteriza a globalização, como já comentamos, têm sido frequentes práticas representacionais estereotipadas dos imigrantes. Posteriormente ao 11 de setembro recrudesceu a construção de muçulmanos e do Islão como o Outro das sociedades ocidentais, descrevendo-os como fundamentalistas, terroristas, sexistas, militantes, antidemocráticos, violentos, homens-bomba, sequestradores, ortodoxos e fanáticos (Dunn, 2001). Os estereótipos dominantes retratam os homens como terroristas ou extremistas estrangeiros (e, mais recentemente, locais), enquanto as mulheres são construídas como reprimidas, que precisam de ser libertadas da opressão patriarcal e da violência (Alsultany, 2012).

Outras minorias étnicas que se constituem como imigrantes em países de economia desenvolvida (latinos, africanos, asiáticos, sobretudo chineses) recebem frequentemente um tratamento mediático que as classifica como ameaça à ordem social, associando-as ao desemprego, à delinquência, à pobreza, à violência (Cogo, 2002). Dessa forma, os meios de comunicação apresentam os imigrantes pelo viés do receio e do medo. Afinal, "a estereotipagem está associada ao poder e à hegemonia e, apesar de circunstancialmente atingir os poderosos, incide preferencialmente sobre os mais fracos e desprotegidos" (Ferin, 2012, p. 109). Os estereótipos negam a possibilidade de qualquer discurso significativo sobre eles ou com eles, e asseguram uma exclusão continuada. Esta noção é, mais facilmente, observada quando as desigualdades de poder fazem com que o grupo dominante possa empregar estratégias representacionais sem enfrentar uma concorrência discursiva à altura (Hall, 1997).

Consideramos que a representação é, portanto, o espaço, por excelência, onde se dão a construção e a constituição de identidades, coletivas e individuais, em vez de ser simplesmente um reflexo secundário das identidades sociais já formadas. Segundo Hall (1997) a representação é parte essencial do processo por meio do qual os sentidos são produzidos e partilhados num dado contexto sociocultural. Representar é, em suma, dar sentido ao mundo por meio da linguagem, permitindo a correlação de conceitos com 
objetos, pessoas e eventos e a transformação de pensamentos em palavras, gestos, imagens e sons.

Tendo em conta a revisão de literatura que fizemos, analisaremos a cobertura da Folha de S. Paulo do surto de ébola a partir dessa discussão teórica e dos procedimentos metodológicos que detalharemos na próxima seção.

\section{Metodologia}

A análise presente neste artigo é realizada a partir dos princípios da semiologia dos discursos sociais. Tal como elaborado por Pinto (2002), essa prática de análise de discursos privilegia a ideia do contexto como eixo estruturante. Por entender o discurso como o conjunto de textos articulados numa prática discursiva, partimos do princípio de que o discurso é, ao mesmo tempo, processo de comunicação e prática social. As análises enfocam os processos de produção de sentido como práticas sociais contextualizadas (Pinto, 2002). Essa perspetiva considera toda a produção sentidos como um ato histórico: não a significação de uma realidade estática de um sujeito solitário, mas uma intervenção discursiva ativa, condicionada por circunstâncias sociais e históricas precisas. Nesse sentido, o destino do discurso é "o que está implícito e não dito", o que não está nele (Bakhtin, 2003).

Pinto (2002) considera que são três os modos de enunciação: mostrar, interagir e seduzir. A demonstração refere-se à construção do referente, do universo do discurso ou do mundo, do objeto sobre o qual se fala. A interação diz respeito ao estabelecimento dos vínculos de interação sociocultural necessários para se dirigir ao interlocutor. A sedução, por fim, corresponde ao processo de distribuição de afetos a serem reconhecidos pelo enunciatário. Para a nossa análise, privilegiaremos as relações entre enunciado e enunciação, entre texto e contexto, no que diz respeito ao processo de construção do referente. Destacaremos marcas enunciativas do processo de representação realizada pela Folha de S. Paulo relativamente à imigração africana e, particularmente, do imigrante guineense no contexto da cobertura do ébola, em 2014. Identificaremos o tipo de caraterização, a escolha de palavras e o uso de metáforas utilizadas para definir a doença, a imigração e o imigrante em questão. Faremos isso por meio de marcas enunciativas, isto é, de pistas deixadas na superfície textual que nos permitirão compreender os processos sociais de produção de sentidos e, assim, situá-los a diferentes níveis de contextualização (situacional, institucional e sociocultural). O nosso objetivo não é apenas "mostrar como" os discursos são o que são, mas "explicar porquê" os discursos são o que são. Afinal, os discursos não relatam só os fenómenos de que falam, mas, ao falar deles de modo específico, constroem-nos enquanto objetos (Foucault, 2006). Esse é outro princípio que orienta a nossa análise - o da propriedade dos discursos construírem realidades.

Para atingir esse objetivo, considerámos, especificamente, os textos publicados sobre a suspeita de contaminação por ébola do guineense Soulyname Bah. Falamos de um total de 9 textos, distribuídos da seguinte forma: no dia 10 de outubro, 1, no dia 11, 3, no dia 13, 2 e no dia 14, 1. Esse segundo momento da análise focou mais o estudo da 
relação entre texto e contexto de enunciação, a partir de marcas linguísticas (verbais e não verbais). No final, além de mostrar como o jornal abordou o acontecimento, podemos explicar, à luz de reflexões teóricas sobre as relações entre media, risco e mobilidade humana no contexto atual da globalização, as motivações para a representação do imigrante como risco para a saúde dos brasileiros.

\section{A cobertura da Folha de S. Paulo sobre o surto de Ébola em 2014}

Mapeamos o jornal Folha de S. Paulo no período de 1 de janeiro até 31 de dezembro de 2014. Identificamos um volume de 189 textos que se referiam ao tema "ébola" (ver Tabela 1). Localizamos dentro deste corpus uma nítida predominância do tema discutido na editoria internacional do jornal ${ }^{3}$, conhecida como "Mundo" e também na editoria/ caderno "New York Times". Tal revela-nos uma abordagem do jornal ao assunto como algo que respeita mais ao exterior do Brasil do que como algo interno, objeto de discussão na nação brasileira. ${ }^{4}$

\begin{tabular}{ll}
\hline \multicolumn{1}{c}{ MÊs } & \multicolumn{1}{c}{$\begin{array}{c}\text { Nú MERO DE textos } \\
\text { SOBRe Ébola }\end{array}$} \\
\hline Janeiro & - \\
\hline Fevereiro & - \\
\hline Março & - \\
\hline Abril & 1 \\
\hline Maio & 1 \\
\hline Junho & - \\
\hline Julho & 8 \\
\hline Agosto & 53 \\
\hline Setembro & 25 \\
\hline Outubro & 73 \\
\hline Novembro & 15 \\
\hline Dezembro & 13 \\
\hline TOTAL & 189 \\
\hline úmero de textos sobre ébola publicados em 2014, por mês
\end{tabular}

Consideramos também importante mencionar ter sido possível observar no levantamento efetuado que os textos sobre o ébola tinham predominantemente um caráter mais noticioso do que opinativo. Podemos ilustrar essa informação recorrendo a um olhar mais quantitativo: nos 189 textos identificados entre janeiro e dezembro de 2014, somente 18 eram de géneros textuais jornalísticos mais opinativos - estando estes

\footnotetext{
${ }^{3}$ As editorias representam o espaço no jornal em que os textos estão localizados. Variam, no enanto, segundo a linha editorial do jornal, podendo receber designações distintas e agrupar temas com arranjos particulares. A Folha de S. Paulo tende a tratar de questões internacionais na editoria "Mundo", nos cadernos "New York Times" e no "Melhor da Gazeta Russa", mas isso não é irredutível, ocasionalmente um tema internacional pode ocupar outras editorias do jornal.

${ }^{4}$ A Folha de S. Paulo tende a tratar de questões internacionais na editoria "Mundo", nos cadernos "New York Times" e no "Melhor da Gazeta Russa", mas isso não é irredutível. Ocasionalmente um tema internacional pode ocupar outras editorias do jornal.
} 
distribuídos entre: editoriais, cartas de leitores ou artigos assinados. Logo, os demais textos apresentados, de caráter mais informativo - totalizando 170 textos - foram apresentados em formato de notas, notícias ou reportagens, sendo alguns deles acompanhados de ilustrações, infográficos ou fotografias sobre o tema. O mês de outubro foi expressivamente o mês com maior publicação de textos sobre o assunto.

\section{AS REPRESENTAÇÕES DO IMIGRANTE GUINEENSE E A CONSTRUÇÃO DO OUTRO}

O nosso período de análise focou textos publicados sobre o ébola e a suspeição de um caso no Brasil. Analisamos as matérias jornalísticas publicadas na Folha de S. Paulo sobre o possível caso no Brasil, entre 10/10/2014 - data da notícia publicada no jornal sobre o primeiro caso de suspeita de ébola no Brasil: "Brasil registra $1^{\circ}$ caso suspeito de ébola" (Folha S. Paulo, Editoria "Cotidiano", p. C1) - e 14/10/2014-data em que o jornal noticia o resultado do segundo exame realizado em paciente com suspeita de ébola e em cujo diagnóstico o ébola não é confirmado: "Novo exame descarta caso de suspeita de ébola no Brasil" (Folha S. Paulo, Editoria Mundo, p. Ag).

\section{O PRIMEIRO CASO DE SUSPEITA DE ÉbOLA NO BRASIL}

A 10 de outubro o jornal traz uma pequena chamada sobre o ébola: "Cidade do PR isola africano suspeito de estar com ébola". O texto não é acompanhado de nenhuma imagem e menciona que "um africano, da Guiné" fora isolado por uma unidade de saúde (na quinta, 9 de outubro) por haver suspeita de que ele estivesse contaminado com o vírus do ébola. Também há uma informação do Ministério da Saúde sobre os sintomas apresentados e a comunicação de que o mesmo será transferido para o Rio de Janeiro.

O texto da chamada aumenta a dramaticidade em torno da periculosidade do paciente:

Um africano da Guiné, de 47 anos, com suspeita de estar com ébola" que "chegou ao Brasil no dia $1^{\circ}$ de setembro, teve febre nos últimos dois dias, mas sem hemorragia ou vômitos. (Folha de S. Paulo, 2014, 10 de outubro, p. $\left.A_{1}\right)$

A articulação dos seguintes léxicos (isola, africano, suspeito, ébola) demonstra a naturalização de metáforas no discurso médico e, particularmente, no modo como o jornalismo aborda questões médicas. Isolamento deriva do latim insula. Entre seus significados, está "ilha". A partir daí, foi associada à palavra a ideia de ficar sem comunicação, não manter contacto com outras pessoas e manter-se afastado. O isolamento, como prática médica, é, nesse sentido, metafórico. Ao ser isolado, o paciente continua a manter contacto com determinados profissionais de saúde para receber tratamento e pode, eventualmente, receber visita de familiares. A questão é que há uma mudança de orientação semântica: se "insula" é substantivo, "isolado" é adjetivo. Ou seja, um diz respeito à própria caraterística estrutural de um ser ou ente (a ilha é afastada do 
continente), enquanto o outro se refere a uma atribuição posterior de sentido, a uma qualidade ou caraterística (o paciente isolado). Nesse texto, o isolamento é tanto prática quanto caraterística imputada a africanos, uma vez que estes "podem" estar contaminados pelo ébola. A suspeição provoca a necessidade de afastar "eles" de "nós". Ou, ainda mais, a segurança perpassa pelo isolamento do que é entendido como ameaça à ordem e à saúde.

Como sabemos, a quarentena refere-se a múltiplas formas de contenção e prisão. A quarentena opera, em geral, através da identificação e distanciando as pessoas percebidas como perigosas, submetendo-os a determinados protocolos de tratamento. Foucault (1979) teorizou o desenvolvimento da governança moderna em relação a várias formas de quarentena. A quarentena consiste em identificar e separar os indivíduos com doenças contagiosas graves da vida social e, em seguida, submetendo-os a determinados protocolos de tratamento. A quarentena implica o isolamento. $O$ jornal classificou como acertada essa conduta:

Imediatamente após a comunicação da suspeita, uma equipa de técnicos do ministério foi enviada em um avião da FAB para coordenar o atendimento e fazer a identificação de pessoas que possam ter tido contato com o paciente. (Folha de S. Paulo, 2014, 10 de outubro, p. A1)

Cabe destacar, também, que os sentidos construídos sobre o ébola, ou sobre qualquer outro tema, só se constroem porque se encontram num contexto comunicativo específico que dialoga, a todo instante, com os demais textos que ali estão a ser apresentados. A seleção dos temas que vão ocupar as capas dos jornais já demonstra um construto sobre a realidade por meio de seleção, classificação, hierarquização e direcionamento no modo de entender os acontecimentos do país e do mundo. No caso da composição da capa do jornal no dia 10 de outubro, apesar de uma possível existência do vírus do ébola no Brasil - vírus este que pode ser letal e que já vinha matando muitas pessoas, especialmente no continente africano - não foi considerado pelo jornal Folha de S. Paulo como o grande assunto do dia. As questões político-eleitorais ganharam maior evidência com manchetes nesta data.

$\mathrm{Na}$ ocasião, os dois grandes temas em destaques na capa foram: a) a disputa eleitoral para presidência da República: "País se divide entre Aécio, 51\%, e Dilma, 49\%"; e b) "Tesoureiro recebia propina para o PT, dizem delatores". Este momento no Brasil correspondia a um contexto de acirrada disputa eleitoral à presidência da República brasileira. É interessante destacar que 2014 foi um ano de eleição majoritária no Brasil, e que a noção de contexto deve ser ressaltada no que diz respeito à produção, circulação e apropriação dos sentidos produzidos pelos media. Nesse caso, é preciso ter em consideração que os temas que estavam a ser discutidos mediaticamente podem auxiliar a compreensão sobre o que o jornal produz, onde e como esses temas circulam e como são propostos sentidos ao público pelo jornal. Como estamos a demonstrar, a maneira como a Folha de S. Paulo abordava o ébola associava-se ao contexto eleitoral. Havia uma enorme desconfiança em relação ao modo como o governo federal, considerando 
as denúncias de corrupção durante a presença do PT no poder. Apesar disso, o jornal reconhecia uma certa habilidade do Ministério de Saúde e de outras instâncias governamentais para a condução do controle da doença no Brasil.

Os assuntos ligados às eleições estavam muito constantemente em agenda em 2014 e tais textos disputavam espaço nas páginas dos jornais com os demais temas, inclusive com temas de saúde. Lembramos que em 5 de outubro de 2014 foi realizada a primeira volta das eleições para Presidente da República, Senadores, Deputados (Estadual e Federal) e Governadores de Estados. Diante deste cenário vale observar que os temas relacionados com questões eleitorais pouco destaque conseguiam ganhar nos jornais.

Ao visitarmos a página onde o texto sobre ébola foi publicado, na editoria "Cotidiano" (p. $C_{1}$ ), no mesmo dia 10 de outubro, notamos que o assunto ocupa quase $50 \%$ da página do jornal, dividindo espaço na página com um anúncio de uma loja de design e decoração. O tema "ébola" é construído com um texto que trata a questão da primeira suspeita de ébola no Brasil e mais duas notas que dão conta do tema ébola fora do Brasil. Para a elaboração da notícia sobre o caso de suspeita no Brasil, recorre-se, para além do texto, a imagens para contar a notícia (Folha de S.Paulo, 2014, 10 de outubro, p. C1).

O título da ilustração é: "suspeita de ébola no Brasil - veja como se dá a transmissão da doença e os sintomas". Abaixo desse título é apresentado uma infografia que explica como se dá a transmissão do vírus e uma lista dos sintomas da doença. Além disso, apresenta um pequeno mapa onde se vê um avião se deslocando da Guiné para o Brasil. O primeiro sentido apreendido é o de que aviões que venham da Guiné/África trarão para o Brasil o vírus do ébola. Propõe-se aí, ao imaginário do leitor, a sensação de que todos aqueles que venham da Guiné trazem consigo o vírus da doença, reforçando a noção do risco da doença do "outro" vir contaminar-nos ("nós"), no Brasil.

$\mathrm{Na}$ construção do texto da notícia, também é possível perceber um certo tom de culpabilização do indivíduo pelo facto de ser africano - como se bastasse ser africano para significar um risco à "nossa" saúde, conforme observamos no subtítulo da matéria:

"Em Cascavel (PR), homem vindo da Guiné, na África, foi isolado em unidade de saúde, que teve de ser esvaziada".

Ainda nessa edição o nome do paciente não foi revelado. Ele foi apresentado como:

"Africano, de 47 anos, que chegou ao Brasil no dia 19 de setembro, vindo da África, e passou pela Guiné, seu país de origem" (Folha de S. Paulo, 2014, 10 de outubro, p. C1 [sublinhados nossos]).

Destaca-se também a redundância como estratégia discursiva para reforçar a periculosidade do indivíduo, pela generalização de um evento epidémico à totalidade do continente africano e pela fixação na representação do imigrante como praticamente contaminado por ébola (apenas) por ter vindo de Guiné.

É exemplar naquela passagem a forma como o estereótipo - o "vírus da essência" (Barthes, 2003, p. 71) - reduz toda a variedade de características de um povo, etnia, género, classe social ou grupo a alguns atributos tomados como essenciais (personalidade, 
indumentária, comportamento, comprometimento, linguagem verbal e corporal, propensão a doenças etc.), pretensamente configuradas pela natureza gênica. Assim, o conhecimento sobre o Outro dá-se de forma maioritariamente intuitiva, reforçando a organização discursiva do senso comum (Freire Filho, 2004).

É por meio dessa perceção generalista que a notícia reforça a suspeição e o pânico já no título: "Brasil registra $1^{\circ}$ caso de suspeita de ébola".

Essa formulação é aparentemente paradoxal. O registo é, em geral, realizado a partir de algo efetivamente ocorrido. Fundamental para a noção de risco é que, assim identificado, ele pode ser gerido e a incerteza reduzida. Ao compreender as linhas de causalidade, é possível agir racionalmente para evitá-lo. No campo da saúde pública, a gestão de incerteza é realizada pela "quantificação do risco através de estudos populacionais que calculam a probabilidade de um fenômeno ocorrer" (Lupton, 1995, p. 78).

No discurso jornalístico, a estipulação da responsabilidade perante o sofrimento dependerá do respeito, ao menos parcial, da construção da causa realizada pelo saber científico (Vaz et al., 2007). Com efeito, no jornalismo, o papel do especialista baseia-se na autoridade em relação ao conhecimento, experiência e capacidade de controlar o que parece estar fora de controlo. O ponto importante é que, dentro de uma sociedade de risco, a incerteza é associada ao perigoso, ao ameaçador, ao que deve ser controlado e evitado. Por gerir incertezas, o especialista torna-se essencial para a construção de um sentido de controlo sobre os riscos. Nessa matéria, a voz especializada é a do Ministério da Saúde que justifica o isolamento do seguinte modo: "Segundo o protocolo do Ministério da Saúde, o local foi esvaziado e outros pacientes foram transferidos" (Folha de S. Paulo, 2014, 10 de outubro, p. C1).

\section{IDENTIDADE DO PACIENTE É REVELADA}

No dia seguinte, dia 11 de outubro, o assunto continua a ganhar espaço na primeira página do jornal, com mais destaque que no dia anterior, trazendo como título: "Paciente melhora, e chance de $1^{\circ}$ caso de ébola diminui". O texto está acompanhado de uma foto publicada como destaque na capa do jornal. A imagem traz como legenda: "Em Cascavel (PR), o guineense Souleymane Bah é transferido para o Rio de Janeiro". A fotografia apresenta uma pessoa deitada numa maca, dentro de uma ambulância com três outras pessoas em redor, auxiliando no transporte da maca. Uma imagem que demonstra um forte isolamento de todas as pessoas (que compõem a imagem): todos com roupas, máscaras, luvas que não possibilitam nenhum contato com direto com o corpo do outro. Uma imagem que traduz a frieza e o cuidado pelo isolamento do paciente.

Apesar do título dar conta de uma aparente melhora do estado de saúde do paciente, a imagem contradi-lo, apresentando um cenário de alerta e monitorização de práticas de isolamento médicas. Segundo o próprio jornal (capa), a área técnica do Ministério da Saúde afirma ser "pouco provável" que ele esteja infetado pelo ébola. Essa informação é contraposta visualmente por todo o aparato médico (macacão reforçado, máscara, óculos, dois pares de luvas e cobertura para os sapatos) montado para impedir o contato 
com o paciente e evitar futuras contaminações (Folha de S.Paulo, Capa do dia 11 de outubro de 2014). Como é possível observar, dois médicos utilizam aqueles uniformes para colocar o paciente, também vestido da mesma forma, numa ambulância. Apesar de toda paramentação, a imagem da capa do jornal revela um momento de insegurança. A lógica do risco é preponderante. Ainda no texto de chamada da capa é dito: "foram identificadas 64 pessoas em Cascavel que tiveram contato com o guineense. Moradores se dividem entre apreensão e a tranquilidade" (sublinhado nosso). Ou seja, nem o isolamento do suspeito por estar contaminado era suficiente para garantir a segurança. Esta tinha de ser confirmada pelos exames clínicos. O jornal procura mostrar que a população está divida para com o paciente e parece convidar o leitor a decidir se o paciente está, ou não, contaminado, se oferece, ou não, risco para a saúde. O texto produz, assim, muito mais incertezas e inseguranças do que confiança em relação à condução do evento pelas autoridades sanitárias do país. Dessa forma, parece estar a confirmar o que estava escrito no editorial de 4 de outubro de 2014: o ébola poderia configurar-se como uma crise sanitária muito maior do que aquela que as autoridades estavam a prever. $\mathrm{A}$ Folha de S. Paulo, pelo contrário, estava correta ao manter o clima de desconfiança e medo diante da situação. Nesse mesmo dia, a desconfiança em relação a instituições estatais brasileiras, sobretudo federais, ganhava as páginas do jornal. A manchete do dia foi: "Dilma diz que oposição usa Petrobrás para 'golpe'”. Outros destaques da capa são, por exemplo: "Ex-diretor da Petrobras atuou para campanha do PT no Rio"; "PT barra perguntas de jornalistas, e Folha desiste de debate" ; e "Fiel a si mesmo, Suplicy foi vítima das traições do PT" (remetendo para o artigo de Demétrio Magnoli). Produz-se, dessa forma, um cenário comunicativo. É possível duvidar da autoridade do governo federal e das suas instituições.

É importante ressaltar que já no dia 11 de outubro se revelava na capa do jornal o nome do paciente: "Souleymane Bah". O texto da chamada apresenta, não apenas o nome do imigrante, mas também o carateriza como o "primeiro suspeito de ébola no Brasil". Além de infringir o direito de anonimato, parece que o possível vírus do ébola no Brasil é da responsabilidade do próprio Souleymane Bah. Cria-se uma relação causal: um indivíduo ameaça o coletivo, isto é, "ele" põe-nos a "nós" em risco. Assim, constrói-se o estereótipo e fecha-se o sentido. O jornal dedicou três páginas na editoria "Cotidiano" a discorrer sobre o caso: desde ilustrações/infográficos, à explicação, passo a passo, das medidas tomadas pelo governo brasileiro para atender o paciente com suspeita de ébola - fornecendo informação sobre o dia, horário e local de atendimentos - a um quadro que demonstrava como se dá a transmissão e a evolução da doença. O que chama mais a atenção é a identidade do paciente ser revelada em duas fotografias. Uma é dele na maca, a ser auxiliado por profissionais de saúde, quando o paciente já não está tão escondido e isolado dentro de uma roupa de proteção, tendo uma parte do rosto a descoberto. A outra é a foto de rosto, similar a uma fotografia 3×4 usada em documentos de identificação. Sendo o ébola uma doença tão grave e que inevitavelmente se traduz em sentimentos de risco e pânico, a exposição da imagem do paciente - que até então apenas tem suspeita da doença - contribuiu para desencadear o recrudescimento de 
preconceitos em relação a africanos. A divulgação da imagem do paciente inserta em textos que reforçam o nível de mortalidade por ébola e os riscos de contaminação no país, contribuiu para tornar Souleymane Bah a personificação da ameaça à saúde e da contaminação pelo ébola. No entanto, por não levar em conta o sigilo médico e o direito do paciente de não ter a sua identidade revelada, o jornal contribuiu para a associação entre o continente africano, a etnia e a proliferação da doença, desconsiderando causas estruturais de eventos biológicos e marginalizando populações (Folha de S.Paulo, 2014, 11 de outubro, pp. $\mathrm{C}_{1}, \mathrm{C}_{2}$ e $\left.\mathrm{C}_{4}\right) .^{5}$

Como estratégia de fixação das fronteiras entre "nós" e "eles", o jornal do dia 11 de outubro noticiou as tensões entre a informação de Artur Chioro, ministro da Saúde, que não descartou a contaminação por ébola, dos responsáveis pela área técnica do Ministério, que a consideravam "pouco provável". Nesse cenário de incertezas, o jornal reforçou o estereótipo: "Ainda está pouco clara a rota do paciente, que se diz refugiado político, até chegar ao interior do Paraná" (Folha de S. Paulo, 2014, 11 de outubro, p. C1 [sublinhados nossos]). Sem apresentar qualquer declaração do paciente ou apresentar alguma prova para refutar tal alegação, o jornal demonstra desconfiança em relação ao facto de ele ser refugiado político e implicitamente o acusa de ser imigrante ilegal: "Bah desembarcou em Guarulhos (SP) no dia 19 de setembro, vindo da Guiné (um dos países mais afetados), em voo que fez escala no Marrocos, segundo registros oficiais colhidos pelo governo" (Folha de S. Paulo, 2014, 11 de outubro, p. C1 - sublinhados nossos).

Assim, o jornal articula o surto de ébola com imigração, crime e raça, reforçando uma postura xenófoba. O jornal chega a recriar a trajetória de Souleymane Bah num infográfico, que circunda a matéria sobre 64 pessoas que entram em contato com ele e que deveriam ficar em quarentena. A decisão de ter vindo para o Brasil, saindo da Guiné e passando pelo Marrocos, poderia desencadear um surto de ébola no país: "Ainda está pouco clara a rota do paciente, que se diz refugiado político, até chegar ao interior do Paraná" (Folha de S. Paulo, 2014, 11 de outubro, p. C1 [sublinhados nossos]). Há, aqui, explicitamente uma desconfiança em relação à procedência da pessoa. Embora tenha afirmado e mostrado um documento que comprova ter sido aceite no Brasil como refugiado político, o jornal coloca tal informação sobre suspeita e não a confirma ("que se diz ser"). Desse modo, há veladamente acusação da falha no sistema de segurança das fronteiras e entradas de alguém vindo da África.

Essa construção reforça o estereótipo de que todo continente africano está contaminado pelo ébola. Como forma de controlo social, os estereótipos demarcam e mantêm as fronteiras simbólicas entre o normal e o anormal, o integrado e o desviante, o saudável e o patológico, o cidadão e o estrangeiro, nós e eles. Tonificam a autoestima e facilitam "união de todos "nós" que somos normais, em uma "comunidade imaginária",

\footnotetext{
${ }^{5} \mathrm{~A} 17$ de abril de 2014, uma notícia vinculada pela Agência Brasil, da Empresa Brasil de Comunicação S/A, informava que o Ministério Público Federal no Distrito Federal (MPF/DF) recomendara à Polícia Federal e ao Ministério da Saúde a manutenção do sigilo os dados pessoais de possíveis suspeitos de infeção pelo vírus ébola no Brasil. A imprensa, no entanto, já havia divulgado o nome do paciente e o classificou como suspeito no dia 11. A quebra do sigilo de identidade do paciente vindo da Guiné provocou manifestações racistas e xenófobas contra ele, especialmente em sites de rede social. Informações no site: http:// www.ebc.com.br/noticias/brasil/2014/10/ministerio-publico-federal-recomenda-sigilo-de-dados-de-suspeitos-de-ebola.
} 
ao mesmo tempo em que excluem, expelem, remetem a um exílio simbólico tudo aquilo que não se encaixa, tudo aquilo que é diferente" (Freire Filho, 2004, p. 48). Além disso, tal construção imputa a um indivíduo as consequências negativas evitáveis de suas próprias decisões que aparecem como previsíveis através da probabilidade de acidentes e doenças e, portanto, ao contrário de catástrofes naturais. Ou seja, a novidade da sociedade de risco mundial reside no facto de que nós, mediante as nossas decisões, podemos causar consequências globais que provocam problemas e perigos (Beck, 2010).

Apesar das alegações de autoridades sanitárias de que havia melhora no quadro clínico do paciente e pouca probabilidade de ser contaminação pelo ébola, o jornal reforçou o pânico através da demonstração da preparação de um enorme aparato médico (ambulância, avião da Força Aérea Brasileira, roupas especiais, médicos, enfermeiros) para a sua remoção de uma Unidade de Pronto Atendimento de Cascavel, no Paraná, para o Instituto Nacional de Infectologia Evandro Chagas, no Rio de Janeiro, onde receberia tratamento adequado. O presidente da Sociedade Brasileira de Infectologia, Érico Antonio Gomes de Arruda, considerou o momento propício para "avaliar a eficiência dos procedimentos" (Folha de S. Paulo, 2014, 11 de outubro, p. C4). Dessa forma, há, por parte de uma autoridade médica, a necessidade do reforço dos protocolos de segurança. Assim, o jornal legitimou a seu próprio diagnóstico sobre a proliferação de casos de ébola no mundo. Enquanto autoridades sanitárias entrevistadas pela Folha de S. Paulo afirmavam que era muito improvável o risco de disseminação de ébola no Brasil, o jornal incitava o pânico, confirmando uma desconfiança: "a identificação do primeiro caso suspeito de ébola no Brasil" (Folha de S. Paulo, 2014, 11 de outubro, p. C4). A ambiguidade da matéria é estrutural e pontual. É estrutural na contradição entre o tom da cobertura e a afirmação dos especialistas, e é pontual na medida em que não deixa claro se a contaminação foi autóctone ou não. Mesmo não tendo sido, o modo como se noticia "o primeiro caso suspeito de ébola no Brasil" incita o pânico ou, minimamente, a aumenta a sensação de insegurança diante de uma possível proximidade da doença.

Outra marcação da diferença étnica aparece numa declaração atribuída a Souleymane Bah que ficou hospedado no Albergue André Luís, entidade filantrópica de Cascavel, do dia 21 de setembro até 8 de outubro. Quando perguntado pela psicóloga do local, Fabiane Ferreira, sobre o facto de a sua indumentária ser colorida, teria respondido: "São da África". O texto apresenta Bah da seguinte forma:

"Na terça (7), o sorridente Souleymane Bah, 47, pareceria especialmente feliz com as roupas vibrantes que vestia. "São da África", disse. Dois dias depois, ele foi considerado o primeiro caso suspeito de ébola no Brasil".

(Folha de S. Paulo, 2014, 11 de outubro, p. C2)

A notícia classifica o imigrante como "sorridente" e "especialmente feliz", mas, diante das suspeitas de ser o primeiro caso de ébola no país, demonstra que houve uma mudança as relações da cidade com os estrangeiros: "Fiquei aqui uns 20 dias com ele. E se eu cair doente também?, afirmou o brasileiro Wallison Novaes Ramos, 18" (Folha de S. Paulo, 2014, 11 de outubro, p. C2 [sublinhados nossos]). A presidente da instituição, Tereza 
Cristina Neppel, afirma que o albergue recebe muitos africanos e haitianos, mas que agora as pessoas temem ficar doentes pelo contato com Bah e outros africanos (ver figura 6).

A felicidade do imigrante por estar no Brasil tinha sido "convertida" pelos brasileiros de Cascavel em medo, devido à suspeita de contaminação. Mais uma vez, constrói-se uma relação causal de culpa pelo estado de risco e insegurança: no próprio imigrante. Nesse sentido, é importante observar que uma oposição entre "nós" (brasileiros) e "eles" (africanos) na reportagem. Ao frisar nos créditos do entrevistado a sua nacionalidade, o texto acaba por estabelecer virtualmente a ameaça localizando no guineense a causa de sofrimentos futuros (ver, em anexo, Fig. 6: Folha de S.Paulo, 2014, 11 de outubro, p. C2).

Houve, por exemplo, manifestações xenófobas de leitores do jornal, indignados com a postura do Estado brasileiro: "É absurdo o procedimento do governo brasileiro, enviando toneladas de alimentos, remédios e dinheiro para países com surto de ébola". A justificativa deste leitor, identificado como Heitor Vianna Filho, era que o governo brasileiro deveria concentrar seus esforços no próprio país, que tinha "milhões [que] ainda carecem de alimentação e tratamento médico" (Folha de S. Paulo, 2014, 12 de outubro, p. A3). Assim, tacitamente, o autor do texto ventila a ideia de que os africanos podem morrer num surto de ébola, pois seria mais importante que o governo federal se dedicasse mais aos próprios brasileiros. Essa perceção guarda uma ampla transformação do poder estatal na sociedade moderna.

No processo de globalização do risco nas sociedades ocidentais contemporâneas, os nexos entre segurança e saúde podem ser vistos como um conjunto de entendimentos e práticas que têm impacto sobre o processo político e domínio político mais geral. Em particular, a securitização de saúde leva a questões que estão sendo vistas, quer como ameaças existenciais que exigem medidas excecionais, quer como exigindo procedimentos técnicos e burocráticos, como o isolamento de pacientes suspeitos. Esse processo revela importantes aspetos, no que diz respeito ao papel do Estado e da natureza da política externa e de segurança. Isso resulta na ligação do Estado a uma gama de atividades de saúde pública, incluindo o controlo de doenças infeciosas, a gestão de ameaças biológicas e da contenção de doenças como obesidade, tabagismo, alcoolismo (Elbe, 2010, p. 175). Ao assumir uma dimensão marcadamente epidemiológica, o poder político torna-se ainda mais governamentalizado, na medida em que é reforçada a tendência para gerir o comportamento dos indivíduos e das populações, com vista a maximizar a sua saúde e utilidade económica é reforçada. Essa tendência resulta em novas intervenções médicas: as políticas de vigilância das populações saudáveis e não saudáveis; a triagem de indivíduos de acordo com factores de risco; processos de confinamento e exclusão de indivíduos de risco; o estabelecimento de padrões de normalidade e desvio, com os efeitos estigmatizantes resultantes. Em suma, no interior dos Estados ocidentais, o nexo da entre segurança e saúde está a mudar as noções de soberania e a transformar as políticas externas e de segurança numa "tecnologia para intensificar o controlo médico das populações" (Elbe, 2010, p. 185).

No que concerne aos objetivos do poder, a governamentalização do Estado sinaliza uma mudança da preocupação exclusiva com a proteção e sobrevivência do soberano 
para a otimização dos recursos e das capacidades dos indivíduos e populações (Foucault, 1979). Assim, as autoridades governamentais passaram a compreender a tarefa de governar politicamente como sendo garantir a segurança dos indivíduos e das populações a fim de "aumentar a sua boa ordem, a sua segurança, a sua tranquilidade, sua prosperidade, saúde e felicidade" (Rose, 1999, p. 6). Assim, tem sido possível pensar que ao Estado caberia a proteção e o resguardo de seus cidadãos e não de estrangeiros.

Ainda no dia 12 de outubro, o jornal noticiou que o primeiro teste com o paciente suspeito de estar contaminado por ébola deu negativo. No entanto, o próprio jornal reforçou o facto de que o "homem, vindo da Guiné, estava isolado no Rio". O ministro, em entrevista, ressaltou que nem ele, nem as pessoas com quem teve contacto, apresentam sintomas de ébola e criticou as manifestações racistas nas redes sociais sobre o episódio. Apesar disso, o jornal, ao final da matéria informa que foi ampliado o número de pessoas em observação (de 64 para 163) e que os moradores de Cascavel "evitam lugar que recebeu africano", referindo-se à UPA de Cascavel. Nem mesmo a divulgação do primeiro resultado negativo fez com que a população se tranquilizasse (Folha de S. Paulo, 2014, 12 de outubro, p. A7). Isso demonstra que, por mais que o governo brasileiro tenha reforçado o controlo médico, parece que não era suficiente para garantir a confiança dos cidadãos brasileiros de que estavam, de facto, seguros. Por outro lado, o jornal qualifica positivamente os procedimentos de segurança do governo brasileiro que consistem em realizar um novo teste para se ter a garantia de que a infeção está definitivamente descartada (Folha de S. Paulo, 2014, 12 de outubro, p. A7).

No dia 13 de outubro, o jornal noticiou o resultado de um segundo exame feito no paciente seria divulgado e que, caso desse negativo, o paciente seria retirado do isolamento. O texto reforçava o nome do paciente e lembrava que o mesmo havia desembarcado no Brasil em 19 de setembro, vindo da Guiné e que se tratava de um dos países da África Ocidental mais afetados pelo ébola. Ainda nessa data, uma carta de um leitor respondia a carta de leitor publicada em 12 de outubro. Nesta atual, o leitor classificava como "absurda": "Acho que é um egoísmo sem tamanho alguém afirmar que não devemos mandar ajuda humanitária para quem necessita. Brasileiros, africanos, europeus, asiáticos - são todos seres humanos, como eu e meus irmãos" (Folha de S. Paulo, 2014, 13 de outubro, p. A3).

No dia 14, por fim, o jornal noticiou que novo exame realizado a Souleymane Bah descartou a possibilidade de contaminação por ébola. O paciente, em novo exame, foi testado para malária, dengue e HIV, obtendo resultados negativos.

Apesar dessas negativas, o jornal assegurou que Bah fosse reconhecido como "o primeiro caso suspeito de ébola no Brasil". Por mais que não tivesse sido confirmada a infeção foi representado como um possivelmente doente através da suspeição, fazendo com que aqueles que estiveram com ele ou nos locais em que ele esteve e até mesmo muito brasileiros que acompanharam a cobertura dessa suspeição vivessem um estado de quase-doença, não necessariamente manifestado como mal-estar e que implica a permanência crónica do cuidado (Vaz et al., 2007). Certamente, esse estado generalizado de quase-doença não se manifesta apenas em situações de construção de pânico 
sanitário pela cobertura jornalística. Até mesmo o discurso jornalístico é constituído pelas formações discursivas do cuidado e da segurança medicalizada produzidas dentro da sociedade do risco, em que "nós" devemos alterar nosso estilo de vida para que evitemos doenças no futuro. Entretanto, e além disso, o Estado é cada vez mais definido como responsável por garantir a nossa proteção sistemática contra os riscos, estabelecendo um controle médico das ameaças à saúde.

\section{CONSIDERAÇÕES FINAIS}

Ao longo desse artigo observamos que a construção do estereótipo do imigrante guineense na Folha de S. Paulo se deu a partir da lógica do risco, reforçando a generalizada consideração da África como lugar de risco para a saúde pelo surto do ébola e dos africanos como agentes disseminadores da doença. Assim, transformou-se o ébola num problema africano que apenas diz respeito à comunidade nacional, pois ameaça a segurança sanitária de outras populações. O jornal reforça a conexão entre a cultura africana e o ébola. Essa associação é mais do que uma retórica de transformação da doença numa questão étnica, uma vez que constrói a africanidade como um fator de risco à saúde. Por diversas vezes, como analisamos, as matérias incitavam o pânico, relacionando a origem africana de Soulyname Bah à suspeita de contaminação por ébola. Mesmo quando comprovado que não tinha contraído o vírus, o jornal continuou a caracterizá-lo como o "primeiro caso suspeito de ébola no Brasil". Assim, o imigrante guineense foi representado como a encarnação do risco à segurança, materializando o sofrimento até então distante no quotidiano do país. A construção dessa aproximação do mal também se deu, como demonstramos, na passagem do assunto da editoria internacional para a nacional.

A análise das matérias permitiu observar a construção da oposição entre "nós" (brasileiros) e "eles" (africanos), enfatizando ora de modo implícito ora explícito a segurança e a prevenção no contexto da globalização envolve a vigilância constante das fronteiras como prática de proteção de possíveis ameaças à ordem. Para isso, o jornal trabalhou com diversos estereótipos, sejam eles tomados como positivos (felicidade, alegria, roupas coloridas) ou constituídos como negativos (vindo da África, refugiado político, doente, suspeito). A suspeição foi o eixo central da cobertura. Nesse sentido, cabe um registo importante: na data em que o resultado do segundo exame é noticiado como negativo, o assunto não ganha espaço na primeira página do jornal. Ou seja, o jornal considera que o tema já não merecia mais destaque na capa e não fornece ao assunto notoriedade. Ou seja, quando não foi confirmada a suspeita, passou a não ser mais relevante a cobertura. Isso demonstra o quanto as notícias produzidas foram feitas a partir da lógica do medo e da promoção do pânico social para um possível estado de calamidade pública.

Dessa forma, a cobertura revelou a natureza limiar do ébola, que não é apenas uma realidade biomédica, mas também social. Ao investigar a forma como a Folha de S. Paulo enquadrou esse surto, observamos que o jornal, embora tenha noticiado as ações dos governos e das autoridades sanitárias, teve como foco a questão da segurança diante da 
mobilidade humana. Afinal, como observamos, a globalização levou à conceituação da saúde como uma questão de risco e segurança nacional. Os media usam frequentemente uma linguagem militarista para descrever focos da doença, agora perspetivados como ameaças à segurança. No Brasil, como a Folha de S. Paulo noticiou, o maior foco de atenção e de ameaça era a presença de africanos no país, sobretudo daqueles recentemente vindos da África. O jornal assumiu a postura de certificar os protocolos utilizados pelo governo brasileiro, mas também noticiava que o facto de o suspeito de estar doente e ter tido contacto com outros brasileiros constituía uma preocupação.

Além disso, destacamos que a cobertura da Folha de S. Paulo sobre a suspeita de contaminação por Soulyname Bah deu-se num contexto de acirrada campanha eleitoral para presidente no Brasil, envolvendo uma polarização entre Aécio Neves (do Partido Social Democracia Brasileiro) e Dilma Rousseff (do Partido dos Trabalhadores), candidata à reeleição. No meio de escândalos envolvendo processos de corrupção na Petrobrás, o jornal reconheceu a capacidade do Estado brasileiro se valer de protocolos de segurança (quarentena, traslado aéreo, ambulâncias, roupas especiais, testes) que poderiam evitar possíveis contaminações, caso fosse confirmada a suspeita. O Estado foi, portanto, positivamente avaliado pelo jornal devido à capacidade de prever riscos, de se antecipar a estes e gerir situações de crise. $O$ restabelecimento da ordem social caberia às ações do Estado. $O$ jornal reconhece a eficácia do dispositivo de segurança sanitária do governo brasileiro, mas, tacitamente, demoniza a presença de africanos no Brasil.

Afinal, a cobertura ao longo de 2014 construiu, de modo geral, o ébola como uma doença distante dos brasileiros; e aquando da única possibilidade da entrada do vírus no Brasil, todo um aparato do Estado para cuidar da saúde do paciente suspeito foi mobilizado, o que demonstrava o quanto o governo brasileiro estava atento a todos os detaIhes e cuidados necessários para manter seus cidadãos protegidos do risco de adoecer. O tipo de cobertura feita pela Folha de S. Paulo produziu uma distância intransponível entre "nós" e "eles". Não há qualquer compaixão por Soulyname Bah, mas apenas a necessidade de aferir se ele era ou não uma ameaça para a segurança nacional. Dessa forma, proteger-se tornou-se uma forma de evitar a empatia pelo Outro. É um pretexto para que não se ajude o Outro. Particularmente, no caso que analisamos, o tratamento de Bah era necessário para assegurar a proteção dos brasileiros diante do ébola. Embora as autoridades sanitárias negassem a possibilidade de pandemia e até mesmo de surto de ébola no Brasil, o jornal reforçou a necessidade do estado de alerta. Não houve espaço para promover a compaixão pelo imigrante, mas houve demasiado para promover o medo e a necessidade de dispositivos de segurança./,

\section{REFERÊNCIAS}

Alsultany, E. (2012). The arabs and muslims in the media: race and representation after 9/11. New York: New York University Press.

Appadurai, A. (1996). Dimensões culturais da globalização: a modernidade sem peias. Lisboa: Editorial Teoria.

Bakhtin, M. (2003). Estética da criação verbal. Martins Fontes: Difel. 
Barthes, R. (2003). Mitologias. Rio de Janeiro: Difel.

Beck, U. (2010). Sociedade do risco: rumo a uma outra modernidade. São Paulo: Editora 34.

Bhabha, H. (1998). O local da cultura. Belo Horizonte: Ed. UFMG.

Bradimore, A. \& Bauder, H. (2011). Mystery ships and risky boat people: Tamil refugee migration in the newsprint media. Canadian Journal of Communication, 36(4), 637-661.

Cabecinhas, R. (2007). Preto e branco: a naturalização da discriminação racial. Porto: Campo das Letras.

Castiel, L. D.; Guilam, M. C. R. \& Ferreira, M. S. (2010). Correndo riscos: uma introdução aos riscos em saúde. Rio de Janeiro: Editora Fiocruz.

Castels, S.; Miller, M. (1998). The age of migration: international population movements in the modern world. London: Macmillan Press.

Castells, M. (1999). A sociedade em rede. São Paulo: Paz e Terra.

Cogo, D. (2002). O outro imigrante: das estratégias de midiatização das migrações contemporâneas na mídia impressa brasileira. Ciberlegenda (UFF), 10(1), 1-11.

Elbe, S. (2010). Security and global health. Cambridge: Polity Press.

Ferin, I. (2009). A cobertura jornalística da imigração: para uma teoria da notícia televisiva. Revista Comunicação e Sociedade, 15, 191-214.

Foucault, M. (2006). Arqueologia do saber. Rio de Janeiro: Forense Universitária.

Foucault, M. (1979). Microfísica do poder. Rio de Janeiro: Edições Graal.

Freire Filho, J. (2004). Estereótipo e alteridade: a construção ideológica do Outro nas investigações jornalísticas de João do Rio. Itinerários (UNESP), 22(1), 133-151.

Giddens, A. (2001). As consequências da modernidade. São Paulo: Unesp.

Gonçalves, C. D. (2004). Cientistas e leigos: uma questão de comunicação e cultura. Revista Comunicação e Sociedade, 6, 11-33. doi: 10.17231/comsoc.6(2004).1226.

Hall, S. (1997). The spectacle of the Other. In S. Hall (Ed.), Representation: Cultural Representations and Signifying Practices (pp. 223-290). London: Sage/Open University.

Lerner, K. \& Gradella, P. (2011). Mídia e pandemia: os sentidos do medo na cobertura de Influenza $\mathrm{H}_{1} \mathrm{~N}_{1}$ nos jornais cariocas. Eco-Pós (UFRJ), 14 (3), 33-54.

Lerner, K. \& Sacramento, I. (2012). Ambivalências do risco: a produção da confiança e da desconfiança na cobertura de $\mathrm{O}$ Estado de S. Paulo da campanha nacional de vacinação contra a influenza $\mathrm{H}_{1} \mathrm{~N}_{1}$. Tempo Brasileiro, 188, 39-60.

Lupton, D. (1995). The imperative of health: Public health and the regulated body. London: Sage.

Massey, D.; Arango, J.; Graeme, H.; Kouaouci, A. \& Pellegrino, A. (1993). Worlds in motion: understanding international migration at the end of the millenium. Clarendon: Press Oxford.

Matheus, S. (2010). Uma modernidade-outra ou o hipermoderno. Revista Comunicação e Sociedade, 18, 133145. doi: 10.17231/comsoc.18(2010).992. 
Muller, B. J. (2004). (Dis)qualified bodies: securitization, citizenship and identity management. Citizenship Studies, 8(3), 279-294. doi: DOI:10.1080/1362102042000257005

Natércia, F. \& Massarani, L. (2014). Difundindo notícias ou pânico? A cobertura da gripe $A\left(\mathrm{H}_{1} \mathrm{~N}_{1}\right)$ no Jornal Nacional e no Fantástico. In K. Lerner \& I. Sacramento (Eds.), Saúde e Jornalismo: Interfaces Contemporâneas (pp. 183-191). Rio de Janeiro: Editora Fiocruz.

Organization, Word Health. (2014). Ébola and Marburg virus disease epidemics: preparedness, alert, control, and evaluation (Interim manual version 1.2). Acedido em http://www.who.int/csr/disease/ébola/ manual_EVD/en/.

Pinto, M. J. (2002). Comunicação e discurso: uma introdução à análise de discursos. São Paulo: Hacker Editores.

Rose, N. (1999). Powers of freedom: reframing political thought. Cambridge: Cambridge University Press.

Sacramento, I. \& Lerner, K. (2015) Pandemia e biografia no jornalismo: uma análise dos relatos pessoais da experiência com a Influenza $\mathrm{H}_{1} \mathrm{~N}_{1}$ em O Dia. Revista FAMECOS (Online), 22 (4), 55-70. doi: $10.15448 / 1980-3729 \cdot 2015 \cdot 4 \cdot 19552$

Shamir, R. (2005). Without Borders? Notes on Globalization as a Mobility Regime. Sociological Theory, 23(2), 197-217. doi: 10.1111/j.0735-2751.2005.00250.x

Silva, P. \& Rosemberg, F. (2014). Brasil: lugares de negros e brancos na mídia. In T. Van Dijk (Ed.), Racismo e Discurso na América Latina (pp. 73-118). São Paulo: Editora Contexto.

Silverstone, R. (2002). Por que estudar a mídia?. São Paulo: Edições Loyola.

Turner, B. (2007). The enclave society: Towards a sociology of immobility. European Journal of Social Theory, 10(2), 287-303. doi: 10.1177/1368431007077807

Woodward, K. (2000). Identidade e diferença: uma introdução teórica e conceitual, in T. T. Silva (Ed.), Identidade e Diferenc $\square$ a: A Perspectiva dos Estudos Culturais (pp. 7-72). Petrópolis: Vozes.

Van Dijk, T. (2010). Discurso e poder. São Paulo: Editora Contexto.

Vaz, P., Pombo, M., Fantinato, M. \& Pecly, G. (2007). O factor de risco na mídia. Interface - Comunicação, Saúde e Educação, 11(21), 145-153. doi: 10.1590/S1414-32832007000100013

Vaz, P., Cardoso, J. M. \& Felix, C. B. (2012). Risco, sofrimento e vítima virtual: a política do medo nas narrativas jornalísticas contemporâneas. Contracampo, 25(2), 24-42.

Young, J. (1971). The drugtakers: the social meaning of drug use. London: Paladin.

\section{NOTAS BIOGRÁFICAS}

Igor Sacramento é doutor em Comunicação e Cultura pela Escola de Comunicação da Universidade Federal do Rio de Janeiro (ECO/UFRJ) e investigador do Laboratório de Pesquisa em Comunicação e Saúde do Instituto de Comunicação e Informação Científica e Tecnológica em Saúde da Fundação Oswaldo Cruz (Laces/Icict/Fiocruz).

E-mail: igor.sacramento@icict.fiocruz.br

Fundação Oswaldo Cruz, Instituto de Comunicação e Informação Científica e Tecnológica em Saúde, Laboratório de Pesquisa em Comunicação e Saúde, Av. Brasil, 4036 / Sala 504, Manguinhos, CEP 21040-361, Rio de Janeiro, Brasil. 
Izamara Bastos Machado é mestre em Comunicação e Cultura pela Escola de Comunicação da Universidade Federal do Rio de Janeiro (ECO/UFRJ) e investigadora do Laboratório de Pesquisa em Comunicação e Saúde do Instituto de Comunicação e Informação Científica e Tecnológica em Saúde da Fundação Oswaldo Cruz (Laces/Icict/ Fiocruz).

E-mail: izamara.bastos@icict.fiocruz.br

Fundação Oswaldo Cruz, Instituto de Instituto de Comunicação e Informação Científica e Tecnológica em Saúde, Laboratório de Pesquisa em Comunicação e Saúde, Av. Brasil, 4036 / Sala 504, Manguinhos, CEP 21040-361, Rio de Janeiro, Brasil.

* Submetido: 08-04-2015

* Aceite: 02-07-2015 